\title{
Quando a intenção de comunicar supera 140 caracteres
}

Antonia Alves Pereira

Especialista em educação a distância (SENAC-RJ), mestranda em Ciências da Comunicação (ECA-USP). Pesquisadora do Núcleo de Comunicação e Educação (NCE-USP).

E-mail: antoniaalvesjor@yahoo.com.br

Resumo: $\mathrm{O}$ artigo é resultado da monografia \#Eadsunday: Educação a Distância em discussão aos domingos - um estudo de caso de uma experiência bem-sucedida no Twitter, realizada como exigência de trabalho de final da disciplina Comunicação, Educação e Linguagem do Programa de Pós-graduação em Ciências da Comunicação (PPGCOM) da Universidade de São Paulo (USP), ministrada pelo professor Adilson Citelli. Seu foco educomunicativo insere-se na apropriação da linguagem dessa ferramenta pelos educadores, identificando seu perfil demográfico e tecnológico, ao mesmo tempo, comparando essa linguagem com aquela a que estão acostumados na modalidade de educação a distância. O resultado da pesquisa foi apresentado na Conferência Online de Informática Educativa <http:// www.coied.com>, entre os dias 07 e 19 de fevereiro de 2011, através de um e-poster.

Palavras-chave: Educomunicação, Twitter, linguagem, polifonia, educação a distância.
Abstract: The article is the result of the monograph \#Eadsunday: E-Learning in Discussion on Sundays - a case study of a successful experience on Twitter, performed as the final work requirement of the course Communication, Education and Language of the Programa de PósGraduação de Ciências da Comunicação (PPGCOM) by Universidade de São Paulo (USP), given by Professor Adilson Citelli. His focus educomunicativo is part of the assimilation of this tool by educators, identifying their technological and demographic profile at the same time, comparing this with that language that are used in the form of distance education. The research result was presented at the Conference on Computers in Education Online <http://www.coied.com> between 07 and 19 February 2011, in an e-poster.

Keywords: Educommunication, Twitter, language, polyphony, distance training.

A monografia \#Eadsunday: Educação a Distância em discussão aos domingos um estudo de caso de uma experiência bem-sucedida no Twitter foi construída em dois meses de observação, de pesquisa etnográfica e de sistematização, resultado da disciplina Comunicação, Educação e Linguagem do Programa de Pós-Graduação em Ciências da Comunicação (PPGCOM) da Universidade de São Paulo (USP), ministrada pelo professor Adilson Citelli. A ênfase recaiu sobre a relação entre comunicação e educação a partir da interface da linguagem, resgatando os teóricos da linguagem, da comunicação e da educação.

A escolha do tema levou em consideração o fato do Twitter apresentar 
comunicação \& educação • Ano XVI • número 2 • jul/dez 2011

pesquisadora utilizar ativamente a ferramenta para divulgar a educomunicação. Para tanto, foi selecionada uma rede bem articulada no espaço - a comunidade \#eadsunday, criada por educadores da Educação a Distância (EAD) que se reúnem desde novembro de 2009, aos domingos, para discutir o assunto e divulgar eventos, bem como links interessantes. A pesquisa ${ }^{1}$ transcorreu durante os meses de outubro e novembro de 2010, por meio de uma investigação etnográfica das discussões e de um questionário on-line para identificar o perfil demográfico e tecnológico dos usuários, bem como a maneira como se deu a apropriação do espaço em vista da EAD.

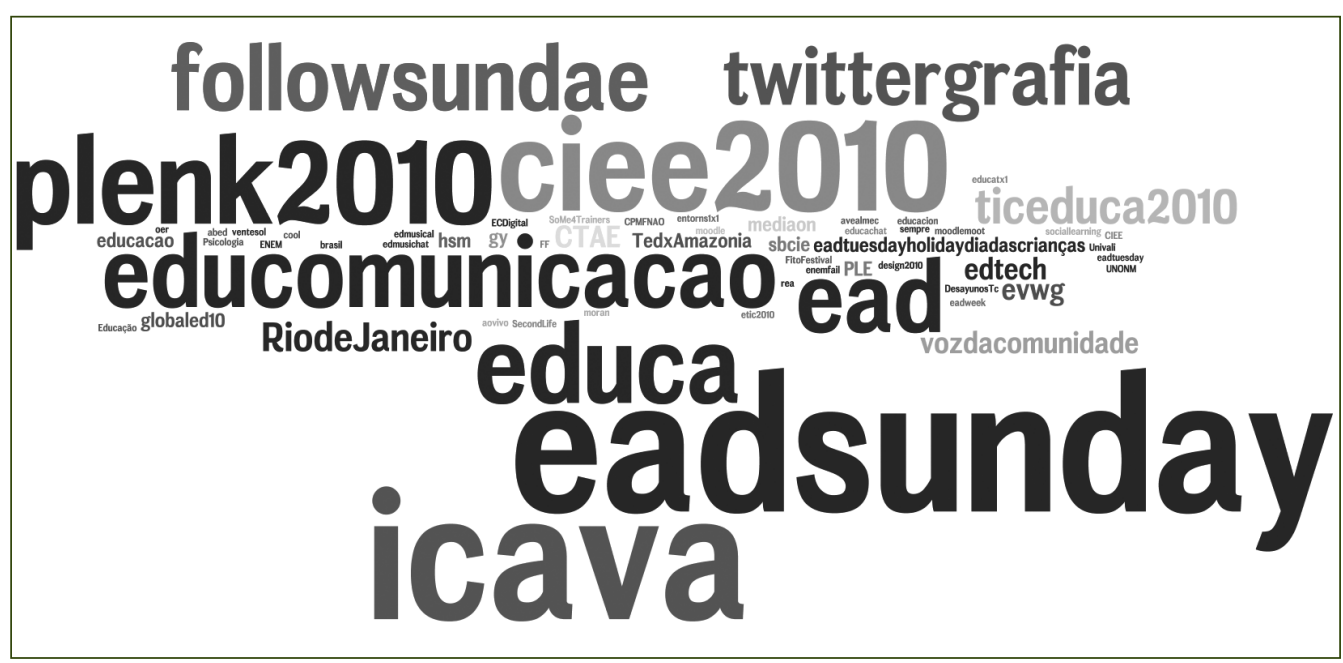

Chamada para o questionário, à época da pesquisa.

As hashtag são palavras-chave antecedidas pelo símbolo "\#”, que designam o assunto o qual está se discutindo em tempo real no Twitter. As hashtags viram hiperlinks dentro da rede e são indexáveis pelos mecanismos de busca. Sendo assim, usuários podem clicar nas hashtags ou buscá-las em mecanismos como o Google para ter acesso a todos que participaram da discussão. No nosso caso, a palavra-chave \#eadsunday é a junção de duas palavras EAD (Educação a Distância) e sunday (domingo, em inglês).

1. Disponível em: <http:// antoniaalves.blogspot. $\mathrm{com} / \mathrm{search} / \mathrm{label} /$ eadsunday>.

2. SOUZA, Mauro Wilton. O lugar social da comunicação mediática. In: SOARES, Ismar de Oliveira (coord.). Caminhos da educomunicação. 2 . ed. São Paulo: Salesiana, 2003. p. 21-34

\section{LINGUAGEM, POTENCIALIDADE EDUCOMUNICATIVA}

Aqui e agora! - cada vez mais essa expressão tem sentido onipresente, pois não é preciso mais estar em um determinado local geográfico para que o ser humano possa estar presente, participando ativamente de projetos, de conversas amenas ou aprofundadas no circuito de suas escolhas prediletas. Isso só é possível graças ao universo que se desdobra com as Tecnologias de Comunicação e Informação (TIC) potencializadas pela internet.

Por sua vez, as TIC se desdobram em múltiplas ferramentas com suas linguagens específicas que podem dar novo sentido à interação entre as pessoas pela apropriação de suas funcionalidades e do capital social que é gerido nesses espaços. Assim se deu com a história da comunicação. Segundo Souza ${ }^{2}$ 
perpassou três grandes idades: primeiro era mediada pelos sons, gestos e signos escritos (diálogo em comunidade); no segundo momento deixa de ser mediada para ser mediática (diálogo a distância); e em seu terceiro, deixa de ser apenas mediática e coletiva para se tornar digital.

Levy lembra que o conhecimento digital se dá pela "apropriação do conhecimento no espaço das novas tecnologias eletrônicas de comunicação e informação" . A apropriação pode ser visualizada historicamente nos movimentos de educação popular e comunicação popular oriundos dos anos 1970, primórdios da inter-relação comunicação e educação.

Ao final da década de 1990, com as pesquisas do Núcleo de Comunicação e Educação (NCE/USP) organizadas sob a coordenação do professor Ismar de Oliveira Soares, percebeu-se claramente que estava surgindo um novo campo de intervenção social. Isso apontava que a "educação para a comunicação, o uso das tecnologias na educação e a gestão comunicativa transformam-se em objeto de políticas educacionais, sob a denominação comum de educomunicação"'.

Trabalhar as TIC a partir da perspectiva educomunicativa é optar por uma atuação democrática, desenvolvendo para isso um ecossistema comunicativo que possibilite a ampliação do coeficiente comunicativo que supõe uma teoria da ação comunicativa "que privilegie o conceito de comunicação dialógica".

Das áreas de intervenção da educomunicação, a mediação tecnológica é o recorte desta pesquisa por tratar da potencialidade dos aparatos tecnológicos e da EAD. Todavia, o foco desta pesquisa recairá sob o prisma da linguagem para vislumbrar sua potencialidade nas enunciações, enunciados e nas manifestações da mesma entre os coenunciadores do processo de comunicação. Isso porque os conceitos de jogos de linguagem e dos usos em seus diversos contextos, de maneira especial no contexto da cibercultura, estão fazendo aflorar cada vez mais redes sociais com laços fortes e fracos, fechadas e abertas, conversacional e informacional.

A comunicação é essencialmente linguagem que se manifesta em códigos, signos, em jogos, usos e contextos, como atestam os filósofos da teoria da linguagem que têm, em Ludwig Wittgenstein, um precursor nessa área. Ele trabalhava os conceitos de jogos de linguagem, usos e contexto que apontam para a provisoriedade dos consensos, pois um enunciado não significa nada em si mesmo, pois se faz nas relações (jogo) que a linguagem permite na prática cotidiana.

É dessa perspectiva filosófica que surgem as teorias dos Atos de fala (John Langshaw Austin) e da Ação comunicativa (Jünger Habermas). A primeira constatando que não cabe à linguagem apenas descrever o mundo ou refletir sobre si própria, mas promover a comunicação. Enquanto a segunda reconhece que a linguagem é "concebida como prática socialmente construída, alimentada pela capacidade de promover consensos a partir de movimentos dialógicos ativadores de relações intersubjetivos" ${ }^{6}$.

Bakhtin concebe que o significado é constituído pelas interações entre sujeito, história e cultura, pois "a interação verbal constitui a realidade fundamental
3. LEVY apud KENSKI, Vani Moreira. Tecnologias e ensino presencial e a distância. 2. ed. Campinas: Papirus, 2003. p. 38.

4. SOARES, Ismar de Oliveira. Caminhos da educomunicação na América Latina e nos Estados Unidos. In: SOARES, Ismar de Oliveira (coord.). Caminhos da educomunicação. 2. ed. São Paulo: Salesiana, 2003. p. 35.

5. Ibid., p. 43.

6. CITELLI, Adilson. Comunicação e linguagem: diálogos, trânsitos e interditos. Matrizes, ano 2, n. 1, p. 20, 2008. 
comunicação \& educação • Ano XVI • número 2 • jul/dez 2011

7. Ibid., p. 24.

8. Ibid., p. 24.

9. BAKTHIN, Mikhail. Marxismo e filosofia da linguagem. Trad. Michel Lahud e Yara Frateschi Vieira. São Paulo: Hucitec, 1981. p. 55.

10. RECHDAN, Maria Letícia de Almeida. Dialogismo ou polifonia? Ciências Humanas, v. 9, n. 1, I semestre 2003 . Disponível em: <http:// www.unitau.br/scripts/ prppg/humanas/download/dialogismo-N1-2003 $\mathrm{pdf}>$. Acesso em: 3 nov. 2010.

11. FERREIRA, Maria Beatriz. A linguagem e os processos de enunciação, dialogismo e polifonia. Olhar de Professor, v. 7 n. 1, 2004, p. 67-75. Disponivel em: <http://www. revistas2.uepg.br/index. php/olhardeprofessor/ article/viewArticle/1415> Acesso em: 3 nov. 2010.

12. SANTAELLA, Lúcia. Navegar no ciberespaço: o perfil cognitivo do leitor imersivo. São Paulo: Paulus, 2004. p. 171 da linguagem"7. Dessa forma, a pesquisa bakthiana em torno da interatividade da linguagem é acompanhada dos conceitos de dialogismo e polifonia. $\mathrm{O}$ primeiro Citelli entende como o elemento instituidor da linguagem, uma vez que o "texto que produzimos, sendo nosso, é também uma sequência do vasto diálogo no qual nos inserimos e ajudamos a fomentar". Isso confirma Bakthin, que afirma ser no processo de interação verbal e social que se criam os signos, resultados de um consenso entre os indivíduos.

Para este autor cada enunciação, "cada ato de criação individual é único e não reiterável, mas em cada enunciação encontram-se elementos idênticos aos de outras enunciações no seio de um determinado grupo de locutores" ${ }^{\prime \prime}$. Isso porque a enunciação gera um processo de compreensão que é uma forma de diálogo que "ilustra o movimento dialógico da enunciação, a qual constitui o território comum do locutor e do interlocutor" ${ }^{10}$.

Nesse contexto social, é possível que surjam vozes polêmicas que também podem ser entendidas nos dias de hoje como intertextualidade. Citando Fiorin e Savioli, Ferreira aponta que todo texto é produto de criação coletiva e que ler criticamente um texto exige do leitor uma história de leitura que o leve à descoberta dessas outras vozes, como também "o confronto entre elas, a fim de que se possa formar o próprio ponto de vista a respeito do tema enfocado"11.

No seio do ciberespaço, as enunciações se dão de maneira interativa, dialógica e interdiscursiva, dependendo do grau de liberdade que o espaço permitir, pois a comunicação mediada por computador (CMC) incentiva a participação, a expressão e o senso de comunidade. O ciberespaço propicia fluxos de signos e jogos de linguagem, pois "põe a nu o verdadeiro caráter dialógico da linguagem que não se confunde, como se pensa com dois egos que se defrontam para negociar significados depositados em suas mentes"12.

\section{TWITTER, UM ESPAÇO DE APROPRIAÇÃO}

O Twitter é uma rede social e servidor para microblogging. Permite aos seus usuários enviar e receber atualizações pessoais de outros contatos (em textos de até 140 caracteres, conhecidos como tweets), por meio do website do serviço, por SMS e por softwares específicos de gerenciamento. As atualizações são exibidas no perfil de um usuário em tempo real e também enviadas a outros seguidores que tenham assinado para recebê-las. O serviço é gratuito pela internet, entretanto, usando o recurso de SMS, pode ocorrer a cobrança pela operadora de telefonia. Desde sua criação em 2006 por Jack Dorsey, o Twitter ganhou notabilidade e popularidade por todo mundo.

\section{FERRAMENTAS DO TWITTER}

O Retweet permite replicar uma determinada mensagem de um usuário para a lista de seguidores, dando crédito a seu autor original. Um botão chamado retwittear fica disponível no site, que faz o envio automático da mensagem para 
a lista. Antes, os usuários realizavam a função de forma manual, acrescentando um $R T$ ao lado da @alcunha de quem escreveu. Quando um texto é retweetado, o termo $R T$ aparece em negrito no início da mensagem.

Já o Twitter List é um recurso que permite ao usuário criar listas compartilháveis de usuários e dinamizar a leitura dos tweets, já que torna possível ler o conteúdo postado por grupos de seguidores. Nas Trending Topics, ou TTs surge numa lista em tempo real com os nomes mais postados no Twitter pelo mundo todo. Valem para essa lista as hashtags (\#) e nomes próprios. O recurso de Trending Topics usa por padrão a abrangência total (worldwide), mas também é possível filtrar por países como Argentina, Austrália, Brasil, Canadá, Estados Unidos, Itália, Alemanha, Espanha, Reino Unido e outros, ou cidades como Boston, Londres, Los Angeles, Miami, Nova York, Rio de Janeiro, São Paulo e outras.

Para Recuero, os sites de redes sociais não são algo novo, "mas uma consequência da apropriação das ferramentas de comunicação mediada pelo computador pelos atores sociais" ${ }^{13}$. Nesse sentido, a apropriação do Twitter se dá "menos como rede de conversação e mais como rede de informação"14. Portanto, ele não é uma rede social, mas uma ferramenta que agrega redes em seu espaço, o que leva a crer que seu valor está no patamar de ser um filtro social de informações potencializando a circulação das mesmas.

Segundo Comm, "alguém que use com sucesso a mídia social não apenas cria conteúdo; cria conversações. E essas conversas criam comunidade" ${ }^{15}$. Por sua vez, essa comunidade ou essas redes começam a funcionar como algo que qualifica, filtra, recomenda e discute a informação que circula no ciberespaço. Portanto, uma informação retwittada passa pelo crivo da qualificação, ou seja, "um julgamento de valor ou observação daquele que a passa"16.

Por ser uma rede social ou de informação em que muitas pessoas interagem, seria educomunicação? Não necessariamente. Para que o conceito possa ser vivenciado em sua plenitude é preciso que haja aumento efetivo do coeficiente comunicativo do grupo, ou seja, é preciso uma interação dialógica, interdiscursiva e colaborativa entre todos os participantes, e não apenas entre alguns. Ficamos apenas no questionamento, uma vez que este não é o foco deste artigo.

\section{AMBIENTE CARREGADO DE SIGNIFICADOS}

Os participantes adentram ao espaço colocando em cada mensagem (tweet) a expressão \#eadsunday. Esse filtro é o que possibilita diálogo em meio às milhares de mensagens inseridas a cada instante, levando os interessados em determinado assunto a estabelecer conversas com seus pares. Isso pode ser visualizado na mensagem: "ñ estou na \#eadsunday mas acompanhando via @Twitter daqui do \#TedxAmazonia" - o usuário disse claramente que se interessa pelos assuntos: \#eadsunday e \#TedxAmazonia.

As palavras acima são hashtag inseridas numa mesma mensagem. São consideradas nessa pesquisa como vozes que vêm e vão de acordo com a participação dos usuários e seu interesse em determinado momento. Sob a
13. RECUERO, Raquel. Redes sociais na Internet. Porto Alegre: Sulina, 2009a. p. 102. (Coleção Cibercultura.)

14. RECUERO, Raquel, Por que o Twitter é tão popular no Brasil?. In: Site ponto mídia, 2010. Disponível em: <http:// www.pontomidia.com. $\mathrm{br} / \mathrm{raquel} /$ arquivos/por que_o_twitter_e_tao_popular_no_brasil.html>. Acesso em: $31 \mathrm{dez} .2010$

15. COMM, Joel. O poder do Twitter: estratégias para dominar seu mercado e atingir seus objetivos com um tweet por vez. Tradução Leonardo Abramowicz. São Paulo: Cortez, 2009. p. 3.

16. RECUERO, Raquel. As redes sociais como filtro. In: Digestivo cultural. 2009b. Disponível em: <http://www.digestivocultural.com/ensaios/ ensaio. asp? codigo $=300>$. Acesso em: 31 out. 2010. 
comunicação \& educação • Ano XVI • número 2 • jul/dez 2011

perspectiva bakthiniana, são tidas como vozes de acordo com os interesses do grupo. Elas foram observadas nos meses pesquisados, através de Nuvem de tags ou nuvem de etiquetas ou palavras, uma lista hierarquizada visualmente, uma forma de apresentar os itens de conteúdo de um website. As pessoas em geral podem categorizar páginas web, fotos e vídeos com qualquer etiqueta que faça sentido. $\mathrm{O}$ uso das etiquetas na web foi difundido por sites como Technorati, del.icio.us e Flickr. No caso da pesquisa com as hashtags no \#eadsunday, ganharam destaque as seguintes palavras, como demonstra a nuvem da figura abaixo:

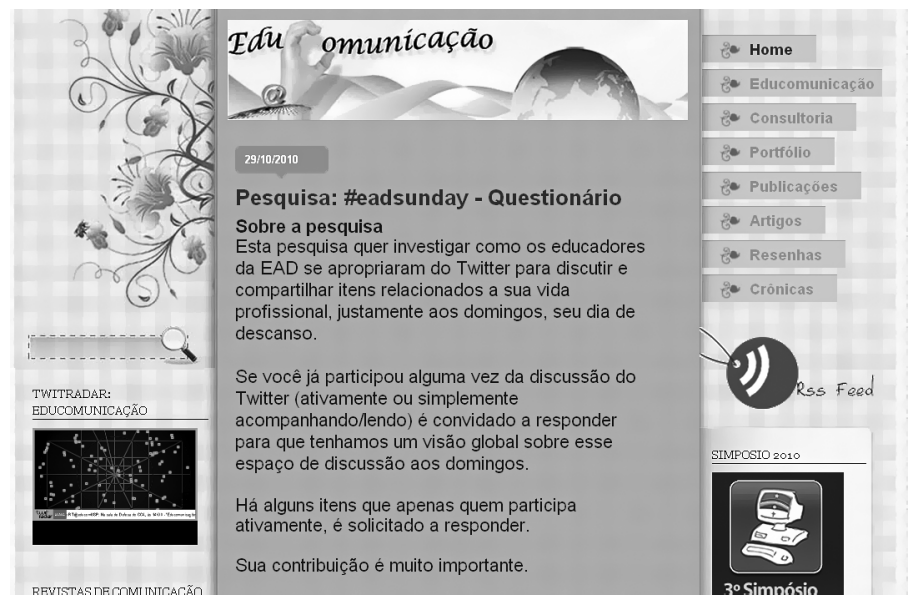

Nuvem de tags com as hashtags no \#eadsunday.

É interessante perceber que as discussões não param aos domingos, pois, ao longo da semana, recebem novas interações e artigos nos blogs dos participantes. Observou-se o número de tweets postados, os perfis que mais contribuíram com o ambiente e sua repercussão. Apenas 29 dos 104 participantes responderam ao questionário on-line da pesquisa, no entanto, os dados se mostraram similar à presença no ambiente. Os perfis que mais participaram, postaram 59\% das enunciações, 958 das mensagens entre o total de 1.633 tweets. Vale destacar que @joaomattar ${ }^{17}$ e @ daisygrisolia ${ }^{18}$ twittaram 386 e 231 tweets, respectivamente, o que demonstra o compromisso de valorização desse espaço de discussão com sua efetiva participação.

Por ser uma pesquisa etnográfica, considerei o olhar de aproximação do pesquisador como objeto de estudo. Perguntei e eles responderam sobre seu perfil demográfico e tecnológico, sobre a linguagem da EAD versus do Twitter, sobre sua apropriação da ferramenta. Observei e constatei: as maiores presenças de temas e de pessoas; a apropriação se dando no processo; as conversas paralelas em meio à chuvarada de links; o aparecimento de hashtags; a aceitação da pesquisa \#eadsunday - pois durante a mesma fui informando sobre os passos e procedimentos; observei a interação e as relações tecidas no espaço.

Dos 104 perfis, 68 membros efetivos twittaram informações ou links, ou, João Mattar foi idealizador do espaço e continua a motivá-lo. Disponível em: <http://www. twitter.com/joaomattar>.

18. Daisy Grisólia (http:// www.twitter.com/daisygrisolia) cultiva uma capacidade de mediar conversas e processos. ainda, apenas retwittaram $(R T)$ ou mencionaram (@) alguém numa mensagem. Outros ainda apareceram nas pesquisas realizadas nos blogs sobre a história do \# eadsunday, mas nos meses investigados não estiveram nas discussões. Há um equilíbrio entre homens e mulheres participantes. A grande maioria reside no Brasil, mas há participantes de Portugal, Espanha, Alemanha, Nova Zelândia, Venezuela e Equador. 


$\begin{array}{ccc}\text { Usuários } & \text { Tweets } & \% \\ 104 & & 100 \% \\ 78 & \text { Menos de } 10 & 75 \% \\ 16 & \text { De } 11 \text { a } 50 & 15 \% \\ 3 & \text { De } 51 \text { a } 99 & 3 \% \\ 5 & \text { Acima de } 100 & 5 \%\end{array}$

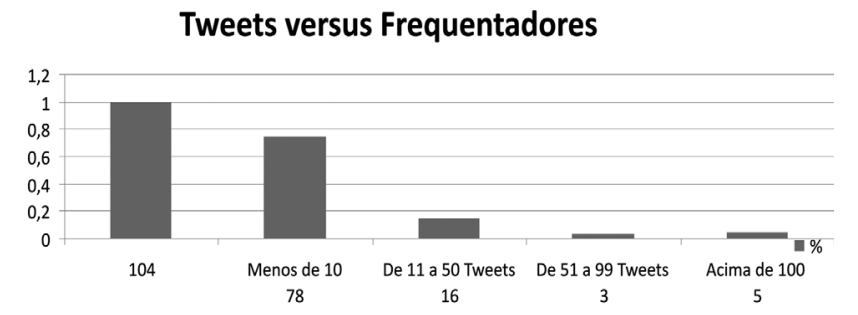

Tweets versus frequentadores.

Uma das linguagens do Twitter, como já dissemos, é o $R T$, que é praticado pelos participantes do \#eadsunday quando consideram uma informação interessante, o que corrobora com o que Recuero ${ }^{19}$ afirma sobre as mensagens passarem por um crivo de qualificação. Eles sentem-se bem escrevendo em 140 caracteres, apesar de algumas vezes utilizarem a prática de postar tweets seguidos para explanar uma ideia ou ainda abreviar palavras.

O espaço de apropriação é marcado pela intenção de compartilhar aspectos da EAD, chamando atenção para os eventos da área em nível nacional e internacional. Tanto as vozes/hashtags como as enunciações são manifestações do pensamento de educadores que acreditam nessa modalidade de ensino, portanto, enunciam, comunicam e interagem a partir desse universo teórico. Apesar disso, discordam com determinadas práticas da modalidade, trazendo ao debate essas divergências, consideradas saudáveis pelos participantes.

Apesar de ser dito que não há um líder, percebe-se a presença de algumas pessoas que dão o direcionamento da discussão. Ao ser questionado sobre o que significa o \#eadsunday, há uma unanimidade afirmando que é um espaço de troca de links. No entanto, percebe-se que é mais que isso, é um espaço de troca de informações, conhecimentos e conversas interativas entre os participantes. Talvez pela limitação da ferramenta com a inserção de apenas 140 caracteres a cada vez - algumas questões não são pontuadas objetivamente ou ficam sem discussão. Esse é um ponto que poderia ser aprofundado em estudos posteriores.

A discussão não para aos domingos, continua por toda a semana, agregando comentários, $R T$ e menções ao assunto e novos links. Muitas vezes pulam do Twitter para artigos em blogs dos participantes como uma forma de registrar as discussões que podem virar eventos. O espaço é também utilizado como uma forma de socorro por aqueles que querem saber alguma informação ou dominar uma ferramenta. Acredito que o espaço poderia ser melhor trabalhado em conversas paralelas ou discussões abertas sobre determinadas temáticas que acabam ficando esquecidas diante da tempestade de links por meio de tweets e RTs disseminados entre os links.

Uma pesquisa futura poderia investigar o espaço como extensão do dialogismo das práticas das instituições das quais esses educadores participam; averiguar como os educadores utilizam as dicas, links e conversas do \#eadsunday em sua docência; identificar se alguns eventos divulgados teriam maior repercussão se tivessem sido realizados apenas por meios tradicionais; e, por fim, estudar os links disponibilizados no ambiente como caminhos efetivos de aprimoramento profissional.

19. RECUERO, Raquel. As redes sociais como filtro. In: Digestivo cultural. 2009b. Disponível em: <http://www.digestivocultural.com/ensaios/ ensaio. asp? codigo $=300>$. Acesso em: 31 out. 2010. 
comunicação \& educação • Ano XVI • número 2 • jul/dez 2011

\section{REFERÊNCIAS BIBLIOGRÁFICAS}

BAKTHIN, Mikhail. Marxismo e filosofia da linguagem. Trad. Michel Lahud e Yara Frateschi Vieira. São Paulo: Hucitec, 1981.

CITELLI, Adilson. Comunicação e linguagem: diálogos, trânsitos e interditos. Matrizes. Revista do Programa de Pós-graduação em Ciências da Comunicação da Universidade de São Paulo, ano 2, n. 1. São Paulo, ECA/USP, 2008.

COMM, Joel. O poder do Twitter: estratégias para dominar seu mercado e atingir seus objetivos com um tweet por vez. Trad. Leonardo Abramowicz. São Paulo: Cortez, 2009.

KENSKI, Vani Moreira. Tecnologias e ensino presencial e a distância. 2. ed. Campinas: Papirus, 2003.

SANTAELLA, Lúcia. Navegar no ciberespaço: o perfil cognitivo do leitor imersivo. São Paulo: Paulus, 2004.

SOARES, Ismar de Oliveira. Caminhos da educomunicação na América Latina e nos Estados Unidos. In: SOARES, Ismar de Oliveira (Coord.). Caminhos da educomunicação. 2. ed. São Paulo: Salesiana, 2003.

SOUZA, Mauro Wilton. O lugar social da comunicação mediática. In: SOARES, Ismar de Oliveira (coord.). Caminhos da educomunicação, cit.

\section{ENDEREÇOS ELETRÔNICOS}

FERREIRA, Maria Beatriz. A Linguagem e os Processos de Enunciação, Dialogismo e Polifonia. Olhar de professor, v. 7, n. 1, 2004, p. 67-75. Ponta Grossa. Disponível em: <http://www.revistas2.uepg.br/index.php/olhardeprofessor/ article/viewArticle/1415>. Acesso em: 3 nov. 2010.

RECHDAN, Maria Letícia de Almeida. Dialogismo ou Polifonia? Ciências Humanas, v. 9, n. 1, I semestre 2003. Disponível em: <http:/ /www.unitau.br/scripts/prppg/ humanas/download/dialogismo-N1-2003.pdf>. Acesso em: 3 nov. 2010.

RECUERO, Raquel. Redes sociais na internet. Porto Alegre: Sulina, 2009. (Coleção Cibercultura.) Disponível em: <http://www.redessociais.net/>. Acesso em: 10 out. 2010.

. As redes sociais como filtro. In: Digestivo cultural. 2009a. Disponível em: $<$ http: $/ /$ www.digestivocultural.com/ensaios/ensaio.asp?codigo $=300>$. Acesso em: 31 out. 2010.

Por que o Twitter é tão popular no Brasil? In: Site ponto mídia. 2010. Disponível em: <http://www.pontomidia.com.br/raquel/arquivos/por_que_o_ twitter_e_tao_popular_no_brasil.html . Acesso em: 31 out. 2010.

; ZAGO, Gabriela. RT, por favor: considerações sobre a difusão de informações no Twitter. Fronteiras, v. 12, n. 2, maio/ago. 2010. Disponível em: $<$ http://www.fronteiras.unisinos.br/pdf/88.pdf>. Acesso em: 10 nov. 2010. 